\title{
Psychological Stress and BMI in the Prevalence of Uterine Leiomyoma Among Young Adult Women: Results from Project ELEFANT
}

\section{Bibo Yuan}

Tianjin Medical University General Hospital

\section{Ruixue Song}

Tianjin Medical University

Timothy M. Barrow

University of Sunderland https://orcid.org/0000-0003-4551-3857

Junkai Fang

Tianjin institute of medical\& pharmaceutical sciences

Elena Colicino

Icahn School of Medicine at Mount Sinai

Citlalli Osorio-Yáñez

Universidad Nacional Autónoma de México: Universidad Nacional Autonoma de Mexico

\section{Ying Zhang}

Tianjin Medical University General Hospital

\section{Chen Li}

Tianjin Medical University

\section{Peng-Hui Li}

Tianjin University of Technology

Liqiong Guo ( $\nabla$ yingqidao@163.com )

Institute of Disaster Medicine, Tianjin University https://orcid.org/0000-0002-1141-9646

\section{Shike Hou}

Tianjin University

Hyang-Min Byun

Newcastle University

\section{Primary research}

Keywords: Psychological stress, uterine leiomyoma, obesity, young adults, women

Posted Date: October 14th, 2020

DOl: https://doi.org/10.21203/rs.3.rs-89462/v1 
License: (c) (i) This work is licensed under a Creative Commons Attribution 4.0 International License. Read Full License 


\section{Abstract}

Background: Uterine leiomyoma (UL) is a benign tumour with a prevalence of $4-21 \%$ in Western populations and UC occurrence is associate with impaired quality of life. Few studies have studied on psychological stress with the prevalence of UL in non-Western populations. We sought to identify the association of psychological stress with the prevalence of UL and mediation by BMI.

Methods: Analysis was performed in a cross-sectional, population-based Project Young ELEFANT study. We analysed clinical data collected from young Chinese women (age 20-40; $n=178205$ ) who were residents of Tianjin, China. Work-related, social and financial stress were evaluated by questionnaire and categorised by intensity (none, low, intermediate, and high). Odds ratios of UL were determined by binary logistic regression models adjusted for age at enrolment, smoking, passive smoking, alcohol consumption, BMI, education, occupation, residence, age at menarche, parity, oral contraceptive use, and diagnosis of type 2 diabetes and hypertension.

Results: UL prevalence in young adult women was associated with psychosocial stress by cause and intensity. High levels of work-related, social and financial stress were associated with ORs $(95 \% \mathrm{Cl})$ of $1.72(1.41,2.10), 1.48(1.18,1.84)$ and $1.44(1.11,1.88)$ respectively. The risk of UL with psychosocial stress showed interaction with $\mathrm{BMI}$, with underweight women at greatest risk.

Conclusions: In young adult Chinese women, psychological stress is associated with UL prevalence. While BMI was positively associated with UL incidence, underweight and healthy weight women with psychosocial stress showed highest risk of UL.

\section{Introduction}

The context of social determinants of mental health, such as gender and income inequality, differ between low- and middle-income countries (LMIC) and those in high income countries (HIC).[1, 2] Studies on the effects of psychological stress have been mainly conducted in HIC, despite a large health disparity in LMIC.[3] One cause of psychosocial stress that is particularly relevant to LMIC is rapid modernisation and urbanisation, which not only modifies the physical environment but also human behaviour in response to it.[4,5] Adapting to a new environment can induce psychological stress in differing ways and intensities. Young adults are particularly vulnerable to suffering from the social and financial stress associated with the transition to an independent life, including building their own career (often associated with a heavy workload).[6] Psychological stress is known to impact upon the body's immune and endocrine systems, which may be of particular consequence to young adult women of reproductive age. Stress induces activation of the hypothalamic-pituitary-adrenal axis that is associated with suppression of the hypothalamic-pituitary-gonadal axis through decreased GnRH secretion, subsequently leading to disruption of the ovarian cycle.

Uterine leiomyoma (UL) are benign smooth muscle tumours.[7, 8] Most of cases show no or only minor symptoms, thus there are a large number of undiagnosed women with the disease. Subsequently, 
estimates of the prevalence of the condition have varied considerably between studies, from 4-70\%.[9, 8] Young women with UL are often untreated as the fibroids are rarely malignant, however surgical removal of the uterus or medication are required for those with severe symptoms.[10] Indeed, it is estimated that $20-50 \%$ of symptomatic women with UL endure significant negative social and economic consequences as a result of their condition.[9] Comorbidities associated with UL include iron deficiency, anaemia, hydronephrosis and miscarriage in pregnant women.[11-13] Therefore, better understanding of the risk of UL in vulnerable young adult women is critical for their health and mental wellbeing. Genetic variants, such as those within mediator complex subunit 12 (MED12)[14] and high-mobility group AT-hook 2 (HMGA2),[15] contribute to the risk of UL, but otherwise the cause of the disease remains largely unknown. Various environmental factors, including psychological stress, obesity and diet, are known to increase the risk of UL.[16, 8, 17, 18] A recent case-control study of Chinese women reported that consumption of vegetables and fruits decreases UL risk, while obesity and low occupational intensity increase risk.[19] Perceived racial discrimination among African-American women has been reported to be associated with a modest increase in the prevalence of UL.[20] Self-reported stress levels have similarly been reported to be higher among women with symptomatic UL than those without, but this association differs by ethnicity as it was present among black women but not white women.[21] In a study of Asian women, no such association was reported between UL and stress, depression or feelings of anxiety.[19] However, to date there has been no large-scale study on psychological stress, particularly interacting with other risk factors, with the prevalence of UL in non-Western populations.

Given the sparse literature in this filed, the goal of this study was to explore the association between psychological stress and UL in young Chinese women, stratified by BMI classification, as one of the commonly known risk factors of the disease. In consideration of the different sources and intensities of stress, we examined work-related, social and financial stress that was categorised by its intensity from participants enrolled in ELEFANT project.

\section{Materials And Methods}

\section{Participants}

Project Environmental and LifEstyle FActors iN metabolic health throughout life-course Trajectories (ELEFANT) is composed of three cohorts: newborns; young adults; and the elderly. We utilised data from pre-menopausal women within Young ELEFANT $(n=178205)$ in this study. All participants were residents of Tianjin city, China. Basic demographic and clinical characteristics data were collected during routine health check-ups (Table 1). 
Table 1

Basic characteristics of the study population by uterine leiomyoma

\begin{tabular}{|c|c|c|c|}
\hline \multirow[t]{2}{*}{ Variables } & \multicolumn{2}{|c|}{ Uterine leiomyoma } & \multirow[t]{2}{*}{$P$} \\
\hline & No $(n=171968)$ & Yes $(n=2751)$ & \\
\hline Age (years) & $28.4(4.7)$ & $34.1(5.5)$ & $<0.001$ \\
\hline BMI & $22.6(4.1)$ & $23.6(4.3)$ & $<0.001$ \\
\hline \multicolumn{3}{|l|}{ Smoking status } & \multirow[t]{3}{*}{$<0.001$} \\
\hline yes & 2071 & 77 & \\
\hline no & 169897 & 2674 & \\
\hline \multicolumn{3}{|l|}{ Passive smoking } & \multirow[t]{3}{*}{$<0.001$} \\
\hline yes & 37838 & 1119 & \\
\hline no & 134130 & 1632 & \\
\hline \multicolumn{3}{|l|}{ Alcohol use } & \multirow[t]{3}{*}{$<0.001$} \\
\hline yes & 9888 & 377 & \\
\hline no & 162080 & 2374 & \\
\hline \multicolumn{3}{|l|}{ Education (years) } & \multirow[t]{4}{*}{$<0.001$} \\
\hline$\leq 9$ & 79687 & 883 & \\
\hline $10 \sim 15$ & 28532 & 453 & \\
\hline$\geq 16$ & 63749 & 1415 & \\
\hline \multicolumn{3}{|l|}{ Occupation } & \multirow[t]{4}{*}{$<0.001$} \\
\hline Manual work & 129462 & 1520 & \\
\hline Non-manual work & 34941 & 987 & \\
\hline Unemployment & 7565 & 244 & \\
\hline \multicolumn{3}{|l|}{ Region } & \multirow[t]{3}{*}{$<0.001$} \\
\hline Rural & 127519 & 1420 & \\
\hline Urban & 44449 & 1331 & \\
\hline Age at menarche & $13.9(1.4)$ & $13.5(1.6)$ & $<0.001$ \\
\hline \multicolumn{3}{|c|}{ Oral contraception use } & \multirow[t]{2}{*}{0.0102} \\
\hline yes & 1270 & 32 & \\
\hline
\end{tabular}




\begin{tabular}{|llll|}
\hline Variables & \multicolumn{2}{l|}{ Uterine leiomyoma } & $P$ \\
\hline no & 170698 & 2719 & \\
\hline Parity (times) & & & \\
\hline None & 88875 & 1247 & \\
$\geq 1$ & 83093 & 1504 & $<0.001$ \\
\hline Hypertension & & & \\
yes & 5859 & 312 & $<0.001$ \\
no & 166109 & 2439 & \\
\hline Type 2 diabetes & & & \\
\hline yes & 2153 & 58 & \\
\hline no & 169815 & 2693 & \\
\hline Continuous variables are expressed by means (SD). & \\
\hline
\end{tabular}

\section{Assessment of uterine leiomyoma}

Clinicians at local hospitals examined the participants by Color ultrasound to diagnose UL. The number, location and size of leiomyoma was also recorded by the clinicians. Self-reported leiomyoma was not considered in this study.

\section{Assessment of psychological stress}

Psychosocial stress was assessed by structured questionnaires, with stress categorised by form (workrelated, social, and financial) and intensity (none, low, intermediate and high). The method employed incorporated shortened versions of the Occupational Stress Indicator (OSI)[22] and the Perceived Stress Scale (PSS-10),[23] which has been validated and widely utilised in China and in the world.[24]

\section{Assessment of other variables}

Demographic data, such as age at enrolment, education, occupation, lifestyles (drinking, smoking and passive smoking), age at menarche, oral contraception usage, times of parity and history of hypertension and type 2 diabetes were collected using structured questionnaires. Education was calculated by the maximum years of formal schooling and classified into three categories of $\leq 9,10 \sim 15$ and $\geq 16$ years. Occupation was categorised as manual work, non-manual work and unemployment. The region in which the participants lived was dichotomised into rural and urban according to their registered permanent residence. Cigarette smoking (yes or no) and alcohol consumption (yes or no) were recorded, and passive smoking history dichotomised (current passive smokers vs. former or non- passive smokers). Parity was dichotomised into 0 and $\geq 1$. According to the standard protocol, we recorded anthropometric 
measurements of each participant, and body mass index (BMI) was calculated as weight/height ${ }^{2}$ $\left(\mathrm{kg} / \mathrm{m}^{2}\right)$. Based on the guidelines of the Department of Disease Control, Ministry of Health of the People's Republic of China (PRC), we considered participants with a BMI below 24 as healthy weight, between 24 and 28 as overweight, and a BMI higher than 28 as obese.[25]

\section{Statistical analysis}

Continuous variables were expressed by means (SD) and categorical variables were expressed by number (\%). Binary logistic regression analyses were performed to estimate the odds ratios [9] and 95\% confidence intervals (Cls) of UL associated with work-related, social and financial stress. Trend tests were implemented to identify trends for ORs by intensity of stress. The associations with BMI were analysed among underweight and healthy weight $(\mathrm{BMI}<24)$ participants and overweight and obese $(\mathrm{BMI} \geq 24)$ participants, with binary logistic regression analyses used to determine whether each of three forms of stress were associated with UL risk within BMI category. All logistic regression analyses were adjusted for age at enrolment, smoking status, passive smoking status, drinking status, BMI, education, occupation, residence, age at menarche, parity, oral contraceptive use, diabetes, and hypertension. All statistical analyses were performed using SPSS 23.

\section{Results}

\section{Uterine leiomyoma prevalence among young Chinese women}

The prevalence of UL in pre-menopausal Chinese women aged between 20 and 50 was $1.6 \%$ (2751/171968). This is lower than reported elsewhere, $[9,8]$ which may be due to the comparatively young age of participants (mean age: 29). BMI was higher among participants with UL $\left(22.56 \pm 4.12 \mathrm{~kg} / \mathrm{m}^{2} \mathrm{vs}\right.$ $\left.23.65 \pm 4.35 \mathrm{~kg} / \mathrm{m}^{2} ; \mathrm{p}<0.001\right)$. The known risk factors for UL of alcohol consumption, first-hand and second-hand tobacco smoke exposure were each confirmed to be positively associated with UL prevalence $(p<0.001)$. Young women with longer in education ( $\geq 16$ years), non-manual occupation and living in urban areas showed greater prevalence of UL. Younger age at menarche, use of the oral contraceptive pill and higher parity were also associated with greater UL prevalence. Women with hypertension or type 2 diabetes also had significantly higher prevalence of UL (Table 1).

\section{Prevalence of UL by BMI}

To understand the association between BMI and UL prevalence, we calculated the odd ratios [9] for UL by BMI category, i.e. underweight, healthy weight, overweight and obese. The analyses were adjusted for age at enrolment, smoking status, passive smoking status, drinking status, education, occupation, region, age at menarche, parity, oral contraceptive use, type 2 diabetes, and hypertension. In young Chinese women, UL prevalence was higher in participants who were overweight (OR $1.30,95 \% \mathrm{Cl}, 1.18-1.42)$ or obese (OR 
$1.31,95 \% \mathrm{Cl}, 1.15-1.50)$ compared to those who are healthy weight (reference) (Table 2). The association with BMI (numerical) and UL prevalence is in eTable 1 in the Supplement.

Table 2

Odds ratios [9] with $95 \%$ confidence intervals ( $95 \% \mathrm{Cls}$ ) for uterine leiomyoma by $\mathrm{BMI}$ and stress.

\begin{tabular}{|c|c|c|c|c|c|}
\hline \multirow[t]{2}{*}{ Variable } & \multicolumn{2}{|c|}{ Uterine leiomyoma } & \multirow[t]{2}{*}{ Crude OR } & \multirow[t]{2}{*}{ Adjusted OR* } & \multirow[t]{2}{*}{$P$ for trend } \\
\hline & No & Yes & & & \\
\hline \multicolumn{6}{|l|}{ BMI } \\
\hline Underweight & 13712 & 112 & $0.62(0.51,0.74)$ & $0.71(0.59,0.87)$ & \multirow[t]{4}{*}{0.049} \\
\hline Healthy weight & 113741 & 1541 & 1.00 (ref) & 1.00 (ref) & \\
\hline Overweight & 32320 & 791 & $1.81(1.66,1.97)$ & $1.30(1.18,1.42)$ & \\
\hline Obesity & 12195 & 307 & $1.84(1.63,2.08)$ & $1.31(1.15,1.50)$ & \\
\hline \multicolumn{6}{|l|}{ Stress } \\
\hline Yes & 36885 & 1209 & $2.87(2.66,3.09)$ & $1.47(1.34,1.62)$ & - \\
\hline No & 135083 & 1542 & 1.00 (ref) & 1.00 (ref) & \\
\hline
\end{tabular}

\section{Psychosocial stress and UL prevalence}

To analyse the association between psychosocial stress and development of UL, we calculated adjusted ORs for UL by form and intensity of stress. Within the Young ELEFANT cohort, $20.63 \%$ of young Chinese women self-reported that they were under work-related stress $(8.73 \%$ low stress, $10.24 \%$ intermediate, and $1.66 \%$ high), $7.70 \%$ that they were enduring social stress ( $6.40 \%$ low, $1.22 \%$ intermediate, and $0.07 \%$ high) and $14.85 \%$ reported financial stress $(7.62 \%$ low, $6.30 \%$ intermediate, and $0.93 \%$ high) (Table 3$)$. The overlap between forms of self-reported psychosocial stress are shown in eFigure 1 in Additional file 1. Participants reporting multiple forms of stress showed significantly higher prevalence of UL (Table 2). Stratification of stress levels by intensity (none, low, intermediate and high) revealed a gradual increase in UL prevalence with higher levels of stress. UL prevalence was also increased by self-reported social stress (OR 1.33, 95\% Cl, 1.18-1.51), with a stronger effect observed with intermediate or high levels (OR 1.48, $95 \% \mathrm{Cl}, 1.18-1.84)$. With work-related stress, the ORs for UL were $1.38(95 \% \mathrm{Cl}, 1.22-1.57), 1.48(95 \% \mathrm{Cl}$, $1.32-1.66)$ and $1.72(95 \% \mathrm{Cl}, 1.41-2.10)$ with low, intermediate and high stress levels, respectively. The ORs of UL associated with financial stress increased steadily with higher levels of stress, ranging from 1.29 (95\% Cl, 1.14-1.46) with low levels to 1.44 (95\% Cl, 1.11-1.88) with high levels (Table 3). An association between stress and UL stratified by work type (manual vs non-manual) is shown in eTable 2 
in Additional file 1. The analyses were adjusted for age at enrolment, smoking status, passive smoking status, drinking status, BMI, education, occupation, region, age at menarche, parity, oral contraceptive use, type 2 diabetes, and hypertension. Associations between stress and UL by age are displayed in eTable 3 in Additional file 1.

Table 3

Odds ratios [9] with $95 \%$ confidence intervals ( $95 \%$ Cls) for uterine leiomyoma by form and intensity of stress.

\begin{tabular}{|c|c|c|c|c|c|}
\hline \multirow[t]{2}{*}{ Variable } & \multicolumn{2}{|c|}{ Uterine leiomyoma } & \multirow[t]{2}{*}{ Crude OR } & \multirow[t]{2}{*}{ Adjusted OR* } & \multirow[t]{2}{*}{ P for trend } \\
\hline & No & Yes & & & \\
\hline \multicolumn{6}{|l|}{ Social stress } \\
\hline None & 159235 & 2301 & 1.00 (ref) & 1.00 (ref) & \multirow[t]{4}{*}{$<0.001$} \\
\hline Low & 10645 & 353 & $2.28(2.04,2.55)$ & $1.33(1.18,1.51)$ & \\
\hline Intermediate & 1969 & 91 & \multirow[t]{2}{*}{$3.21(2.61,3.94)$} & \multirow[t]{2}{*}{$1.48(1.18,1.84)$} & \\
\hline High & 119 & 6 & & & \\
\hline \multicolumn{6}{|c|}{ Work-related stress } \\
\hline None & 137701 & 1609 & 1.00 (ref) & 1.00 (ref) & \multirow[t]{4}{*}{$<0.001$} \\
\hline Low & 14668 & 391 & $2.28(2.04,2.55)$ & $1.38(1.22,1.57)$ & \\
\hline Intermediate & 16908 & 618 & $3.13(2.85,3.44)$ & $1.48(1.32,1.66)$ & \\
\hline High & 2691 & 133 & $4.18(3.49,5.01)$ & $1.72(1.41,2.10)$ & \\
\hline \multicolumn{6}{|c|}{ Financial stress } \\
\hline None & 147270 & 1942 & 1.00 (ref) & 1.00 (ref) & \multirow[t]{4}{*}{$<0.001$} \\
\hline Low & 12772 & 368 & $2.18(1.95,2.44)$ & $1.29(1.14,1.46)$ & \\
\hline Intermediate & 10398 & 375 & $2.70(2.41,3.02)$ & $1.34(1.18,1.51)$ & \\
\hline High & 1528 & 66 & $3.34(2.61,4.27)$ & $1.44(1.11,1.88)$ & \\
\hline
\end{tabular}

\section{High prevalence of uterine leiomyomas in BMI under $24 \mathrm{~kg} / \mathrm{m}^{2}$ with psychological stress}


We observed that BMI and psychological stress were each associated with UL in the previous analysis. To examine the prevalence of UL in under/healthy weight and overweight/obese individuals self-reporting stress, we dichotomised study participants using a BMI threshold of $24 \mathrm{~kg} / \mathrm{m}^{2}$; this is the threshold used to identify overweight/obese individuals according to Chinese guidelines.[25] The prevalence of UL in participants reporting social stress was OR $1.43(95 \% \mathrm{Cl}, 1.25-1.65)$ among those with a $\mathrm{BMI}<24$ and $1.23(95 \% \mathrm{Cl}, 1.02-1.49)$ for those with $\mathrm{BMI}>24$ (Table 4). The ORs for UL with work-related stress were $1.60(95 \% \mathrm{Cl}, 1.41-1.81)$ in under/normal weight participants, and $1.25(95 \% \mathrm{Cl}, 1.08-1.46)$ for overweight/obese participants. Financial stress was associated with increased UL prevalence in both weight groupings, with an OR of $1.41(95 \% \mathrm{Cl}, 1.24-1.59)$ for under/normal weight individuals and 1.18 ( $95 \% \mathrm{Cl}, 1.01-1.38)$ for overweight/obese participants. Thus, we observed that the association of UL with any form of stress was stronger in underweight/normal weight individuals in comparison to overweight and obese ones.

Table 4

Odds ratios [9] with $95 \%$ confidence intervals ( $95 \%$ Cls) for uterine leiomyoma by psychological stress and BMI.

\begin{tabular}{|c|c|c|c|c|c|c|}
\hline & \multicolumn{3}{|l|}{$\mathrm{BMI}<24$} & \multicolumn{3}{|c|}{$\mathrm{BMI} \geq 24$} \\
\hline & \multicolumn{2}{|c|}{$\begin{array}{l}\text { Uterine } \\
\text { leiomyoma }\end{array}$} & \multirow[t]{2}{*}{ Adjusted OR* } & \multicolumn{2}{|c|}{$\begin{array}{l}\text { Uterine } \\
\text { leiomyoma }\end{array}$} & \multirow[t]{2}{*}{ Adjusted OR* } \\
\hline & No & Yes & & No & Yes & \\
\hline \multicolumn{7}{|c|}{ Social stress } \\
\hline No & 117947 & 1362 & 1.00 (ref) & 41288 & 939 & 1.00 (ref) \\
\hline Yes & 9506 & 291 & $\begin{array}{l}1.43(1.25, \\
1.65)\end{array}$ & 3227 & 159 & $1.23(1.02,1.49)$ \\
\hline \multicolumn{7}{|c|}{$\begin{array}{l}\text { Work-related } \\
\text { stress }\end{array}$} \\
\hline No & 102292 & 929 & 1.00 (ref) & 35409 & 680 & 1.00 (ref) \\
\hline Yes & 25161 & 724 & $1.60(1.41,1.81)$ & 9106 & 418 & $1.25(1.08,1.46)$ \\
\hline \multicolumn{7}{|c|}{ Financial stress } \\
\hline No & 109462 & 1147 & 1.00 (ref) & 37808 & 795 & 1.00 (ref) \\
\hline Yes & 17991 & 506 & $\begin{array}{l}1.41(1.24, \\
1.59)\end{array}$ & 6707 & 303 & $1.18(1.01,1.38)$ \\
\hline
\end{tabular}




\section{Interaction between BMI and psychological stress on uterine leiomyoma prevalence}

We examined interactions between BMI and psychological stress upon the prevalence of UL (Table 5). In this study, we observed that interaction between stress and underweight (OR 1.16, 95\% Cl, 1.00-1.34), overweight (OR $0.92,95 \% \mathrm{Cl}, 0.85-1.00)$ and obesity (OR $0.90,95 \% \mathrm{Cl}, 0.81-1.00)$ was significant in increasing the ORs for UL.

Table 5

Interaction between $\mathrm{BMI}$ and stress for uterine leiomyoma risk.

\begin{tabular}{|c|c|c|c|}
\hline \multirow[t]{2}{*}{ BMI classification } & \multirow[t]{2}{*}{ Stress } & \multicolumn{2}{|l|}{ Uterine leiomyoma } \\
\hline & & Crude OR $(95 \% \mathrm{CI})$ & Adjusted* OR $(95 \% \mathrm{Cl})$ \\
\hline \multirow[t]{2}{*}{ Underweight } & no & $0.48(0.42,0.55)$ & $0.71(0.61,0.82)$ \\
\hline & yes & $1.15(1.00,1.34)$ & $1.16(1.00,1.34)$ \\
\hline \multirow[t]{2}{*}{ Healthy weight } & no & 1.00 (ref) & 1.00 (ref) \\
\hline & yes & $1.71(1.61,1.81)$ & $1.26(1.18,1.34)$ \\
\hline \multirow[t]{2}{*}{ Overweight } & no & $1.53(1.42,1.66)$ & $1.20(1.11,1.30)$ \\
\hline & yes & $0.90(0.84,0.98)$ & $0.92(0.85,1.00)$ \\
\hline \multirow[t]{2}{*}{ Obesity } & no & $1.54(1.40,1.71)$ & $1.22(1.10,1.36)$ \\
\hline & yes & $0.92(0.83,1.01)$ & $0.90(0.81,1.00)$ \\
\hline
\end{tabular}

\section{Discussion}

In Chinese young adult women, psychological stress increased the prevalence of uterine leiomyomas in an intensity-dependent manner. High intensity of work-related stress was the strongest risk factor for the disease over other forms of stress. Interestingly, the association of stress with uterine leiomyomas prevalence was higher in under or healthy weight young women than overweight or obesity. To the best of our knowledge, our study is the first to report an association between psychosocial stress and uterine leiomyomas in an Asian population, and the first to identify an interaction with BMI.

Evidence from clinical, molecular and pharmacological studies has supported the implication of the sex hormones in the development and maintenance of uterine leiomyomas, as hormonally-responsive neoplasms.[26, 27] Psychosocial stress may subsequently promote the development of UL through hormonal imbalance, and particularly through the action of cortisol. This stress hormone is released by 
activation of the hypothalamic-pituitary- adrenal gland axis under stress, and in turn regulates the secretion of a number of other hormones, including glucocorticoids, catecholamines, growth hormone, prolactin, oestrogen and progesterone.[28-30] In vitro studies have demonstrated increased secretion of ovarian steroids after stress hormone exposures[31] while, conversely, suppression of circulating gonadotropins and gonadal steroid hormones has been observed in non-human primates undergoing stressful conditions, leading to abnormal menstrual cycle and impairment of reproductive function.[32]. This is supported by evidence from a human population study that increased cortisol levels are associated with altered production of reproductive hormones and subsequently alterations in the menstrual cycle.[33] However, the few studies that have examined the interplay of cortisol and reproductive hormones frequently show contrasting findings, and therefore much further work is required to elucidate the mechanisms underpinning the association between UL and psychosocial stress.

Our study demonstrated a dose-dependent increase in UL risk with higher intensity of stress. While we also observed a differential effect by form of self-reported stress (e.g. financial), these may be proxies for the intensity of stress felt by the individual. The hypothesis that the level of stress endured by an individual is associated with UL risk is further supported by studies elsewhere. Within the Nurses' Health Study, sexual and physical abuse in childhood was demonstrated to be associated with increased risk of UL in premenopausal women, with a dose-response reported between severity and duration of abuse and UL risk.[34] Similarly, Vines et a/ reported an association between the number of self-reported major life events with respect to stress intensity and UL incidence, with higher prevalence among black women with severe stress compared with those no or mild stress.[35]

Previous epidemiological studies report a positive association between BMI and UL,[36, 37] or an inverse J-shaped association.[38] In this study, leiomyoma prevalence was higher among women who were underweight and of a healthy weight in comparison to those who are overweight or obese. Similar results are reported in the Black Women's Health Study, where increased risk of leiomyoma was reported in women with a BMI of $27.5-29.9 \mathrm{~kg} / \mathrm{m}^{2}$ and lower risk in women with a BMI of $\geq 30 \mathrm{~kg} / \mathrm{m}^{2}$, indicating an inverse J-shaped association[38] that has also been reported in Asian women.[39] Psychological stress is known to impair the immune system and is associated with increased body weight.[16] Our observation of an interaction between $\mathrm{BMI}$ and psychosocial stress underlines that a complex interaction exists between key risk factors for uterine leiomyoma.

A limitation of the present study is that cortisol level, as a biomarker of stress, was not available in the study participants. However, this is the first study to report on the effects of different forms and intensities of psychosocial stress upon UL risk using a validated psychological stress measurement in a large number of young women. The data in the present study was also analysed cross-sectionally, and therefore the association between prevalence of UL with stress needs further study to examine causal relationships with genetic factors using follow-up data in a prospective study.

\section{Conclusions}


We report that uterine leiomyoma prevalence in young adult women is increased by psychological stress, with risk greatest among those individuals reporting high intensity of stress. The association was stronger in underweight and healthy weight women in comparison to overweight and obese individuals. Further work is required to elucidate the complex interplay of stress, obesity and hormonal imbalance in the modification of UL risk.

\section{Abbreviations}

UL, Uterine leiomyoma; ORs, Odds ratios; LMIC, low- and middle-income countries; HIC, high income countries; MED12, mediator complex subunit 12; HMGA2, high-mobility group AT-hook 2.

\section{Declarations}

\section{Acknowledgements}

We are extremely grateful to the Tianjin Research Institute for Family Planning which provided the data and samples for the study.

\section{Authors' contributions}

conceptualization, L.G. and S.H.; methodology, J.F. and E.C.; formal analysis, R.S. and B.Y.; investigation, B.Y.; resources, Y.Z., C.L., H.L., R.Z.and X.G.; data curation, B.Y., R.S., J.F., C.O.Y..; writing-original draft preparation, B.Y.and T.M.B.; writing-review and editing, H.M.B., B.Y. and P.H.L.; visualization, S.H., H.M.B and L.G.; supervision, S.H. and H.M.B.; project administration, L.G., S.H. and H.M.B.; funding acquisition, L.G., X.G. and Y.Z.

\section{Availability of data and materials}

The datasets used during the current study are available from the corresponding authors on reasonable request.

\section{Code availability}

All codes from this study are available from the corresponding authors on reasonable request.

\section{Funding information}

This work was supported by National Natural Science of China [81971416], Natural Science Foundation of Tianjin [18JCQNJC11700 and 18ZXDBSY00190].

\section{Competing interests}

All authors declare that they have no competing interests. 


\section{Consent for publication}

Not applicable.

\section{Ethics approval and consent to participate}

All procedures and study protocols were approved by the ethical committee of Tianjin Medical University (TMUhMEC2016022). The study was conducted in accordance with the princples of the Declaration of Helsinki. All participants signed written informed consent before in clusion in the study.

\section{References}

1. Breen KM, Billings HJ, Wagenmaker ER, Wessinger EW, Karsch FJ (2005) Endocrine basis for disruptive effects of cortisol on preovulatory events. Endocrinology 146 (4):2107-2115. doi:10.1210/en.2004-1457

2. Patel V, Prince M (2010) Global mental health: a new global health field comes of age. JAMA 303 (19):1976-1977. doi:10.1001/jama.2010.616

3. Maselko J (2017) Social Epidemiology and Global Mental Health: Expanding the Evidence from High-Income to Low- and Middle-Income Countries. Curr Epidemiol Rep 4 (2):166-173. doi:10.1007/s40471-017-0107-y

4. Cheng HG, Shidhaye R, Charlson F, Deng F, Lyngdoh T, Chen S, Nanda S, Lacroix K, Baxter A, Whiteford H (2016) Social correlates of mental, neurological, and substance use disorders in China and India: a review. Lancet Psychiatry 3 (9):882-899. doi:10.1016/S2215-0366(16)30166-3

5. Bai X, Chen J, Shi P (2012) Landscape urbanization and economic growth in China: positive feedbacks and sustainability dilemmas. Environ Sci Technol 46 (1):132-139. doi:10.1021/es202329f

6. Bortolussi J (2015) Investing in the Health and Well-Being of Young Adults. J Adolescent Health 57 (1):127-127. doi:DOI 10.1016/j.jadohealth.2015.04.019

7. Cramer SF, Patel A (1990) The frequency of uterine leiomyomas. American journal of clinical pathology 94 (4):435-438

8. Stewart EA, Cookson CL, Gandolfo RA, Schulze-Rath R (2017) Epidemiology of uterine fibroids: a systematic review. BJOG 124 (10):1501-1512. doi:10.1111/1471-0528.14640

9. Vilos GA, Allaire C, Laberge PY, Leyland N, Special C (2015) The management of uterine leiomyomas. J Obstet Gynaecol Can 37 (2):157-178. doi:10.1016/S1701-2163(15)30338-8

10. Stewart EA, Nicholson WK, Bradley L, Borah BJ (2013) The Burden of Uterine Fibroids for AfricanAmerican Women: Results of a National Survey. Journal of Womens Health 22 (10):807-816. doi:10.1089/jwh.2013.4334

11. Sparić R (2014) [Uterine myomas in pregnancy, childbirth and puerperium]. Srp Arh Celok Lek 142 (12):118-124 
12. Walker CL, Stewart EA (2005) Uterine fibroids: The elephant in the room. Science 308 (5728):15891592. doi:10.1126/science. 1112063

13. Zimmermann A, Bernuit D, Gerlinger C, Schaefers M, Geppert K (2012) Prevalence, symptoms and management of uterine fibroids: an international internet-based survey of 21,746 women. BMC Womens Health 12:6

14. Makinen N, Mehine M, Tolvanen J, Kaasinen E, Li Y, Lehtonen HJ, Gentile M, Yan J, Enge M, Taipale M, Aavikko M, Katainen R, Virolainen E, Bohling T, Koski TA, Launonen V, Sjoberg J, Taipale J, Vahteristo P, Aaltonen LA (2011) MED12, the mediator complex subunit 12 gene, is mutated at high frequency in uterine leiomyomas. Science 334 (6053):252-255. doi:10.1126/science.1208930

15. Bulun SE (2013) Uterine fibroids. N Engl J Med 369 (14):1344-1355. doi:10.1056/NEJMra1209993

16. Pavone D, Clemenza S, Sorbi F, Fambrini M, Petraglia F (2018) Epidemiology and Risk Factors of Uterine Fibroids. Best Pract Res Clin Obstet Gynaecol 46:3-11. doi:10.1016/j.bpobgyn.2017.09.004

17. Brakta S, Diamond JS, Al-Hendy A, Diamond MP, Halder SK (2015) Role of vitamin D in uterine fibroid biology. Fertil Steril 104 (3):698-706. doi:10.1016/j.fertnstert.2015.05.031

18. Ciebiera M, Wlodarczyk M, Ciebiera M, Zareba K, Lukaszuk K, Jakiel G (2018) Vitamin D and Uterine Fibroids-Review of the Literature and Novel Concepts. Int J Mol Sci 19 (7). doi:10.3390/ijms19072051

19. He Y, Zeng Q, Dong S, Qin L, Li G, Wang P (2013) Associations between uterine fibroids and lifestyles including diet, physical activity and stress: a case-control study in China. Asia Pac J Clin Nutr 22 (1):109-117. doi:10.6133/apjcn.2013.22.1.07

20. Wise LA, Palmer JR, Cozier YC, Hunt MO, Stewart EA, Rosenberg L (2007) Perceived racial discrimination and risk of uterine leiomyomata. Epidemiology 18 (6):747-757. doi:10.1097/EDE.0b013e3181567e92

21. Vines Al, Nguyen TTX, Ta M, Esserman D, Baird DD (2011) Self-Reported Daily Stress, Squelching of Anger and the Management of Daily Stress and the Prevalence of Uterine Leiomyomata: The Ultrasound Screening Study. Stress Health 27 (3):e188-e194. doi:10.1002/smi.1360

22. Siu O-I, Donald I, Cooper CL (1997) The use of the occupational stress indicator (OSI) in factory workers in China. International Journal of Stress Management 4 (3):171-182. doi:10.1007/bf02765322

23. Cohen S, Kamarck T, Mermelstein R (1983) A global measure of perceived stress. J Health Soc Behav 24 (4):385-396

24. Barrow TM, Peng C, Wilson A, Wang H, Liu H, Shen L, Tang NJ, Sae-Lee C, Li PH, Guo L, Byun HM (2018) Psychosocial stress is associated with benign breast disease in young Chinese women: results from Project ELEFANT. Breast Cancer Res Treat. doi:10.1007/s10549-018-4979-4

25. Chen C, Lu FC, Department of Disease Control Ministry of Health PRC (2004) The guidelines for prevention and control of overweight and obesity in Chinese adults. Biomedical and environmental sciences : BES 17 Suppl:1-36 
26. Marsh EE, Bulun SE (2006) Steroid hormones and leiomyomas. Obstet Gynecol Clin North Am 33 (1):59-67. doi:10.1016/j.ogc.2005.12.001

27. McWilliams MM, Chennathukuzhi VM (2017) Recent Advances in Uterine Fibroid Etiology. Semin Reprod Med 35 (2):181-189. doi:10.1055/s-0037-1599090

28. Rein MS, Barbieri RL, Friedman AJ (1995) Progesterone: a critical role in the pathogenesis of uterine myomas. Am J Obstet Gynecol 172 (1 Pt 1):14-18

29. Sozen I, Arici A (2006) Cellular biology of myomas: interaction of sex steroids with cytokines and growth factors. Obstet Gynecol Clin North Am 33 (1):41-58. doi:10.1016/j.ogc.2005.12.005

30. Ranabir S, Reetu K (2011) Stress and hormones. Indian J Endocrinol Metab 15 (1):18-22. doi:10.4103/2230-8210.77573

31. Kornya L, Bodis J, Koppan M, Tinneberg HR, Torok A (2001) Modulatory effect of acetylcholine on gonadotropin-stimulated human granulosa cell steroid secretion. Gynecol Obstet Invest 52 (2):104107. doi:10.1159/000052952

32. Cameron JL (1997) Stress and behaviorally induced reproductive dysfunction in primates. Semin Reprod Endocrinol 15 (1):37-45. doi:10.1055/s-2008-1067966

33. Nepomnaschy PA, Welch K, McConnell D, Strassmann BI, England BG (2004) Stress and female reproductive function: a study of daily variations in cortisol, gonadotrophins, and gonadal steroids in a rural Mayan population. Am J Hum Biol 16 (5):523-532. doi:10.1002/ajhb.20057

34. Boynton-Jarrett R, Rich-Edwards JW, Jun HJ, Hibert EN, Wright RJ (2011) Abuse in childhood and risk of uterine leiomyoma: the role of emotional support in biologic resilience. Epidemiology 22 (1):6-14. doi:10.1097/EDE.0b013e3181ffb172

35. Vines Al, Ta M, Esserman DA (2010) The association between self-reported major life events and the presence of uterine fibroids. Women's health issues : official publication of the Jacobs Institute of Women's Health 20 (4):294-298. doi:10.1016/j.whi.2010.03.009

36. Faerstein E, Szklo M, Rosenshein N (2001) Risk factors for uterine leiomyoma: a practice-based casecontrol study. I. African-American heritage, reproductive history, body size, and smoking. Am J Epidemiol 153 (1):1-10

37. Terry K, De Vivo I, Hankinson S, Spiegelman D, Wise L, Missmer S (2007) Anthropometric characteristics and risk of uterine leiomyoma. Epidemiology 18 (6):758-763

38. Wise LA, Palmer JR, Spiegelman D, Harlow BL, Stewart EA, Adams-Campbell LL, Rosenberg L (2005) Influence of Body Size and Body Fat Distribution on Risk of Uterine Leiomyomata in U.S. Black Women. Epidemiology 16 (3):346-354. doi:10.1097/01.ede.0000158742.11877.99

39. Lee J, Song S, Cho E, Jang H, Jung H, Lee H, Kim S, Kim O, Lee J (2018) Weight change and risk of uterine leiomyomas: Korea Nurses' Health Study. Curr Med Res Opin:1-7

\section{Supplementary Files}

This is a list of supplementary files associated with this preprint. Click to download. 
- Additionalfile1.docx

Page 17/17 